\title{
Mechanism of mass transfer between a bubble initially composed of oxygen and molten glass ${ }^{1}$
}

\author{
F. Pigeonneau* \\ Surface du Verre et Interfaces, UMR 125 Unité mixte CNRS/Saint-Gobain, 39 quai Lucien Lefranc- \\ BP 135, 93303 Aubervilliers Cedex, France
}

\begin{abstract}
The bubble removal from molten glass is an important problem in glass melting process. In this paper, the mass transfer undergone by a bubble rising in molten glass is studied, the multicomponent feature being taken into account. In order to identify the time scaling of the bubble shrinkage, a careful dimension analysis is performed.

A characteristic time to describe the mass transfer for each gaseous species in a bubble is introduced with an alternative expression of the permeability. This new permeability has the dimension of a diffusion coefficient, which is useful to compare to other transport phenomena. From the physical data known for soda-lime-silica glasses, a fast equilibrium state of water between a bubble and molten glass is determined. The opposite situation is observed for nitrogen.

Experimental results giving the bubble size versus time with a dimensionless form leads to a good match at short time whatever the glass nature and the temperature. Finally, a simple equation to determine bubble size as a function of time is given, based on the dimension analysis previously established.
\end{abstract}

Key words: Bubble, chemical processes, glass science, mass transfer, multiphase reactions, dimension analysis

\section{Nomenclature}

Roman symbols

\footnotetext{
${ }^{1}$ DOI:10.1016/j.ijheatmasstransfer.2010.11.049

*Corresponding author: Tel. +33 (1) 483959 99, Fax +33 (1) 48395562.

Email address: franck.pigeonneau@saint-gobain.com (F. Pigeonneau)

Preprint submitted to Int. J. Heat 8 Mass Transfer
} 


\begin{tabular}{|c|c|c|}
\hline Symbol & Definition & Unit (SI) \\
\hline$a$ & bubble radius & $\mathrm{m}$ \\
\hline$a_{0}$ & initial bubble radius & $\mathrm{m}$ \\
\hline$A_{i}^{(D)}$ & coefficient in the diffusion coefficient of gaseous species $i$ & $\mathrm{~m}^{2} \cdot \mathrm{s}^{-1}$ \\
\hline$B_{i}^{(D)}$ & coefficient in the diffusion coefficient of gaseous species $i$ & $\mathrm{~K}$ \\
\hline$A_{i}^{(S)}$ & coefficient in the solubility of gaseous species $i$ & $\mathrm{~mol} \cdot \mathrm{m}^{-3} \cdot \mathrm{Pa}^{-\beta_{i}}$ \\
\hline$B_{i}^{(S)}$ & coefficient in the solubility of gaseous species $i$ & $\mathrm{~K}$ \\
\hline$C_{\mathrm{Fe}^{2+}}^{\infty}$ & molar concentration of reduced iron in molten glass & $\mathrm{mol} \cdot \mathrm{m}^{-3}$ \\
\hline$C_{\mathrm{Fe}^{3+}}^{\infty}$ & molar concentration of oxidized iron in molten glass & $\mathrm{mol} \cdot \mathrm{m}^{-3}$ \\
\hline$C_{i}^{\infty}$ & bulk molar concentration of gaseous species $i$ & $\mathrm{~mol} \cdot \mathrm{m}^{-3}$ \\
\hline$C_{\mathrm{O}_{2}}^{\infty}$ & bulk molar concentration of $\mathrm{O}_{2}$ & $\mathrm{~mol} \cdot \mathrm{m}^{-3}$ \\
\hline$C_{i}^{S}$ & $\begin{array}{l}\text { molar concentration of gaseous species } i \text { on the bubble sur- } \\
\text { face }\end{array}$ & $\mathrm{mol} \cdot \mathrm{m}^{-3}$ \\
\hline $\mathcal{D}_{i}$ & diffusion coefficient of gaseous species $i$ in molten glass & $\mathrm{m}^{2} \cdot \mathrm{s}^{-1}$ \\
\hline$g$ & gravity constant & $\mathrm{m} \cdot \mathrm{s}^{-2}$ \\
\hline$H$ & liquid height & $\mathrm{m}$ \\
\hline$K_{\mathrm{Fe}}$ & $\begin{array}{l}\text { equilibrium constant of the iron oxidation-reduction reac- } \\
\text { tion }\end{array}$ & $\mathrm{mol}^{1 / 4} \cdot \mathrm{m}^{-3 / 4}$ \\
\hline$L_{i}$ & solubility coefficient of gaseous species $i$ & $\mathrm{~mol} \cdot \mathrm{m}^{-3} \cdot \mathrm{Pa}^{-\beta_{i}}$ \\
\hline$n_{i}$ & number of moles in the bubble of gaseous species $i$ & mol \\
\hline$N_{\mathrm{Fe}}$ & $\begin{array}{l}\text { Dimensionless number related to the oxidation-reduction } \\
\text { reaction of iron oxides }\end{array}$ & - \\
\hline$N_{g}$ & total number of gaseous species & - \\
\hline$N_{h}$ & dimensionless number defined as $\rho g H / P_{0}$ & - \\
\hline$N_{\sigma}$ & dimensionless number defined as $2 \sigma /\left(P_{0} a_{0}\right)$ & - \\
\hline$P_{i}$ & partial pressure in the bubble of gaseous species $i$ & $\mathrm{~Pa}$ \\
\hline$P_{0}$ & atmospheric pressure & $\mathrm{Pa}$ \\
\hline$P e_{i}$ & Péclet number related to the gaseous species $i$ & - \\
\hline$P e_{\mathrm{O}_{2}}$ & Péclet number related to $\mathrm{O}_{2}$ & - \\
\hline$P e_{\mathrm{O}_{2}}^{\prime}$ & $\begin{array}{l}\text { modified Péclet number related to } \mathrm{O}_{2} \text { taking into account } \\
\text { the iron oxidation-reduction reaction }\end{array}$ & - \\
\hline
\end{tabular}




\begin{tabular}{|c|c|c|}
\hline$R$ & universal gas constant & $\mathrm{J} \cdot \mathrm{K}^{-1} \cdot \mathrm{mol}^{-1}$ \\
\hline $\mathcal{R}^{\infty}$ & iron reduction state of molten glass & - \\
\hline$S a_{i, 0}$ & saturation of gaseous species $i$ defined at $P_{0}$ & - \\
\hline$S a_{\mathrm{H}_{2} \mathrm{O}, 0}$ & saturation of water defined at $P_{0}$ & - \\
\hline$S a_{\mathrm{O}_{2}}$ & saturation of oxygen defined at the partial pressure $P_{0_{2}}$ & - \\
\hline$S a_{\mathrm{O}_{2}, 0}$ & saturation of oxygen defined at $P_{0}$ & - \\
\hline$S a_{S_{2}, 0}$ & saturation of sulfur dioxide defined at $P_{0}$ & - \\
\hline$S h_{i}$ & Sherwood number of gaseous species $i$ & - \\
\hline$\overline{S h}_{i}$ & $\begin{array}{l}\text { ratio of the Sherwood number of gaseous species } i \text { for a } \\
\text { bubble size } a \text { divided by the Sherwood number of gaseous } \\
\text { species } i \text { for the initial bubble size } a_{0}\end{array}$ & - \\
\hline$t$ & time & $\mathrm{s}$ \\
\hline $\bar{t}$ & reduced time & - \\
\hline$T$ & temperature & $\mathrm{K}$ \\
\hline$V_{T}$ & terminal rising velocity of the bubble & $\mathrm{m} \cdot \mathrm{s}^{-1}$ \\
\hline$x_{i}$ & molar fraction of gaseous species $i$ in the bubble & - \\
\hline$x_{\mathrm{H}_{2} \mathrm{O}}$ & molar fraction of water in the bubble & - \\
\hline$z$ & local position of the bubble center & $\mathrm{m}$ \\
\hline $\bar{z}$ & normalized local position of the bubble center & - \\
\hline
\end{tabular}

Greek symbols

Symbol

Definition

Unit (SI)

$\alpha$

function of oxygen saturation $S a_{\mathrm{O}_{2}}$ for the computation of the modified Péclet number

$\beta_{i}$ characteristic exponent of gaseous species $i$ in the Henry's law dynamic viscosity of liquid $\mathrm{Pa} \cdot \mathrm{s}$

$\nu \quad$ kinematic viscosity of liquid, equal to $\mu / \rho$ $\mathrm{m}^{2} \cdot \mathrm{s}^{-1}$

$\rho \quad$ liquid density $\mathrm{kg} \cdot \mathrm{m}^{-3}$ 


$\begin{array}{lll}\sigma & \text { surface tension } & \mathrm{N} \cdot \mathrm{m}^{-1} \\ \tau & \text { characteristic time of mass transfer } & \mathrm{s} \\ \tau_{i} & \text { characteristic time of mass transfer of gaseous species } i & \mathrm{~s} \\ \bar{\tau}_{i} & \text { reduced characteristic time of mass transfer of gaseous } & - \\ & \text { species } i \text { defined as } \tau_{i} / \tau_{\mathrm{O}_{2}} & \\ \tau_{\mathrm{O}_{2}} & \text { characteristic time of mass transfer of oxygen } & \mathrm{S} \\ \tau_{\mathrm{Sh}_{2} \mathrm{O}_{2}} & \text { characteristic time of shrinkage of an oxygen bubble } & \mathrm{S} \\ \bar{\tau}_{\mathrm{SO}_{2}} & \text { reduced characteristic time of mass transfer of } \mathrm{SO}_{2} \text { defined } & - \\ & \text { as } \tau_{\mathrm{SO}_{2}} / \tau_{\mathrm{O}_{2}}\end{array}$

\section{Introduction}

The dispersion of gaseous inclusions in a continuous liquid phase is an important problem in handling materials such as molten glass. During glass melting, bubble removal, achieved by buoyancy forces, is necessary but difficult due to the high dynamic viscosity even at high temperature: it is larger than $10 \mathrm{~Pa} \cdot \mathrm{s}$ at $1400{ }^{\circ} \mathrm{C}$. Therefore, "fining" agents are added in raw materials, releasing gases at high temperature, (Shelby [28]). The bubbles grow due to the migration of the "fining" gases from glass into the bubbles. Consequently, the mass transfer process concerning bubbles dispersed in a molten glass must be carefully studied in order to design new efficient furnaces.

The mass transfer around a bubble or a drop has been studied for many years and the state of knowledge can been found in the textbook of Sadhal et al. [26]. In the framework of molten glass, Shelby [28] summed up the key points. He underlined that apart from carbon dioxide coming from the decomposition of raw materials and oxygen, the presence of other dissolved gases in molten glass such as water vapor, sulfur dioxide and nitrogen is an important feature.

As underlined by Mysen and Richet [14], iron is a major polyvalent metal found in natural and industrial glasses. The oxidation-reduction state of iron is carefully controlled in the glass melting process because of its important role in glass color, see [11]. The bubble behavior in molten glass have been studying for many years with the first 
contributions by the group of Greene $[7,8,9,10]$. They developed an experimental device allowing the stabilization and the observation of a bubble. Later, Němec $[15,16]$ developed an experimental method where a single bubble is released in a transparent crucible containing molten glass and its size is recorded via a camera. The aim of this experimental set-up is to follow a bubble undergoing a motion relative to molten glass. More recently, Kloužek and Němec [12] improved the experiment by transferring the bubble from the top to the bottom of the crucible when it approaches the free surface to increase the interaction time between the bubble and molten glass.

Doremus [6] provided one of the first theoretical contributions about the shrinkage of a bubble in molten glass. Readey and Cooper [25] studied, via a finite difference method, the mass transfer taking into account a pure diffusion process with the temporal evolution of the bubble's radius introduced into a numerical model. The modeling of multicomponent bubbles in molten glass had been done by Ramos [24] or more recently by Němec and Kloužek [17] and was summed up by Beerkens [1]. In order to take into account the effect of chemical reactions on the oxygen resorption pointed out by Greene and Lee [9], Subramanian and Chi [29] developed a model where a first-order irreversible reaction was introduced. The role of oxidation-reduction reactions of polyvalent cations had been studied by Yoshikawa and Kawase [30] for an immobile bubble. The oxidationreduction reaction was assumed to be very fast but limited by the diffusion of oxygen according to the first developments of Beerkens and de Waal [3]. It was pointed out by Yoshikawa and Kawase [30] that the bubble growth is enhanced by the oxidationreduction reaction. The chemical coupling between the two phases had been recently studied by Pilon et al. [23] where a population balance equation is used. Recently, the influence of oxidation-reduction reaction on mass transfer around a rising bubble in molten glass had been studied by Pigeonneau [21], and Pigeonneau et al. [22]. It was pointed out both experimentally and numerically that when the iron content increases the mass transfer of bubble is enhanced.

In spite of these many contributions, the role played by the various gases on the bubble size is seldom studied. Moreover, even if numerical simulations are applied to describe bubbles dispersed in molten glass, a scaling analysis is missing. From the point of view of the industrial process, it is very important to know the order of magnitude 
of shrinkage or growth rate of bubbles dispersed in a furnace as a function of the glass nature and the composition of each bubble. Therefore, the purpose of this article is to find the time scale of the mass transfer as a function of various species and glass nature. In order to describe the shrinkage of a bubble initially composed of $100 \%$ of oxygen, a dimension analysis is proposed. The work will be focused on soda-lime-silica glasses with two iron contents.

The model describing the temporal evolution of a bubble in molten glass is briefly recalled in section 2. The dimension analysis is done in $\S 3$. Finally, a conclusion is given in section 4. Appendix A presents the physical and chemical properties taken from the literature and used in this work.

\section{Statement of problem}

As mentioned above, a model for a multicomponent bubble with $N_{g}$ gaseous species has already been described in detail in $[20,22]$ and will be briefly recalled below.

\subsection{Temporal evolution of bubble composition}

The bubble radius, $a$, is determined by solving the implicit equation

$$
\frac{3 R T \sum_{i=1}^{N_{g}} n_{i}}{4 \pi a^{3}}=P_{0}+\rho g(H-z)+\frac{2 \sigma}{a},
$$

where $R$ is the universal gas constant, $T$ the temperature, $n_{i}$ the number of moles of gaseous species $i, P_{0}$ the atmospheric pressure, $\rho$ the glass density, $g$ the gravity, $H$ the liquid height, $z$ the local position of the bubble and $\sigma$ the surface tension. In this last equation, each gaseous species is assigned by the index $i$ varying from 1 to $N_{g}$.

Eq. (1) represents the equilibrium between the pressure given by the ideal gas law and the pressure obtained from the summation of atmospheric, hydrostatic and Laplace pressures. In order to solve eq. (1), the number of moles of each species and the local position, $z$ must be determined.

The quantity $n_{i}$ is evaluated by the following ordinary differential equation

$$
\frac{d n_{i}}{d t}=2 \pi a S h_{i} \mathcal{D}_{i}\left(C_{i}^{\infty}-C_{i}^{S}\right)
$$


corresponding to the mass balance between the bubble and its surrounding. In eq. (2), $\mathcal{D}_{i}$ is the diffusion coefficient, $S h_{i}$ the Sherwood number described below, $C_{i}^{\infty}$ the bulk molar concentration of gaseous species $i$. The molar concentration on the bubble surface, $C_{i}^{S}$, is given by Henry's law:

$$
C_{i}^{S}=L_{i} P_{i}^{\beta_{i}}
$$

where $L_{i}$ is the solubility coefficient, $P_{i}$ the partial pressure in the bubble of species $i$. The exponent, $\beta_{i}$, is equal to unity for most species, but is $1 / 2$ for water since it is chemically dissolved in molten glass [19].

The local position of the bubble is determined by

$$
\frac{d z}{d t}=V_{T}
$$

with molten glass assumed to be static. As in [21], the bubble interface in molten glass is assumed fully mobile. Consequently, the terminal rising velocity of the bubble, $V_{T}$, is given for a "clean bubble" $[5,26]$ by the relationship

$$
V_{T}=\frac{g a^{2}}{3 \nu}
$$

in which, $\nu$ is the kinematic viscosity defined as the ratio $\mu / \rho$ where $\mu$ is the dynamic viscosity of the liquid.

\subsection{Mass transfer coefficients}

The Sherwood number of gaseous species $i, S h_{i}$ in Eq. (2), represents the ratio of the mass transfer with diffusion and advection to the mass transfer without relative motion between the bubble and molten glass. As reported in classical textbooks of Clift et al. [5], and Sadhal et al. [26], the interface mobility plays an important role in mass transfer.

Chemical reactions can be also involved in the mass transfer process. The main conclusion of [21] was the need to define a new mass transfer coefficient for $\mathrm{O}_{2}$ taking into account in the oxidation-reduction reaction of iron oxides defined by [19]

$$
\mathrm{Fe}^{3+}+\frac{1}{2} \mathrm{O}^{2-} \rightleftharpoons \mathrm{Fe}^{2+}+\frac{1}{4} \mathrm{O}_{2}
$$

where, $\mathrm{Fe}^{3+}$ is the oxidized state and $\mathrm{Fe}^{2+}$ the reduced state, $\mathrm{O}^{2-}$ the free oxygen ion and $\mathrm{O}_{2}$ the dioxygen. 


\subsubsection{Sherwood number without reaction}

For the other species, the usual Sherwood number is used, [5, 26]. The Sherwood number of species not participating in the oxidation-reduction reaction of iron oxides and for a fully mobile interface is given by the relationship [5]

$$
S h_{i}=1+\left(1+0.564 P e_{i}^{2 / 3}\right)^{3 / 4},
$$

where the Péclet number, $P e_{i}$, is defined as

$$
P e_{i}=\frac{2 a V_{T}}{\mathcal{D}_{i}}
$$

\subsubsection{Sherwood number with reaction}

The reaction (6) enhances the mass transfer of oxygen where the Sherwood number for $\mathrm{O}_{2}$ have been determined in [21] under assumptions of instantaneous chemical reaction limited by the diffusion of oxygen. As it has been pointed out in [21], the Sherwood number can be written with the same relationship (7) but the Péclet number is replaced by the modified version, $P e_{\mathrm{O}_{2}}^{\prime}$, given by:

$$
P e_{\mathrm{O}_{2}}^{\prime}=P e_{\mathrm{O}_{2}}\left[1+\alpha\left(S a_{\mathrm{O}_{2}}\right) N_{\mathrm{Fe}}\right]
$$

where $\alpha\left(S a_{\mathrm{O}_{2}}\right)$ is defined by

$$
\frac{1}{\alpha}=\frac{1}{3.05 S a_{\mathrm{O}_{2}}^{-0.375}}+\frac{1}{1.28 S a_{\mathrm{O}_{2}}^{-1}}
$$

The oxygen saturation, $S a_{\mathrm{O}_{2}}$, is equal to

$$
S a_{\mathrm{O}_{2}}=\frac{C_{\mathrm{O}_{2}}^{\infty}}{C_{\mathrm{O}_{2}}^{S}}
$$

where $C_{\mathrm{O}_{2}}^{\infty}$, and $C_{\mathrm{O}_{2}}^{S}$ are the bulk and surface oxygen concentrations, respectively.

The dimensionless number, $N_{\mathrm{Fe}}$, is defined as follows

$$
N_{\mathrm{Fe}}=\frac{C_{\mathrm{Fe}^{2+}}^{\infty}\left(1-\mathcal{R}^{\infty}\right) S a_{\mathrm{O}_{2}}^{1 / 4}}{16 C_{\mathrm{O}_{2}}^{S}},
$$

where $\mathcal{R}^{\infty}$ is the reduction state of iron defined by

$$
\mathcal{R}^{\infty}=\frac{C_{\mathrm{Fe}^{2+}}^{\infty}}{C_{\mathrm{Fe}^{2+}}^{\infty}+C_{\mathrm{Fe}^{3+}}^{\infty}} .
$$


In these two last equations, $C_{\mathrm{Fe}^{2+}}^{\infty}$ and $C_{\mathrm{Fe}^{3+}}^{\infty}$ are the bulk molar concentrations of $\mathrm{Fe}^{2+}$ and $\mathrm{Fe}^{3+}$ respectively.

Equations (1), (2), and (4) can been solved numerically to obtain the radius, the position, and the composition of the bubble as it is done in [20, 22]. Here a scaling analysis is addressed to find the time scale occurring in the mass transfer of the bubble. The theoretical prediction will be compared with experimental results recently presented by Pigeonneau et al. [22] for two glasses with a set-up very close to the experiment presented by Kloužek and Němec [12]. A bubble is inflated thanks to a silica tube and observed through a transparent silica crucible with a video-camera. The bubble size is determined by a simple image analysis. The composition of glasses are given in Table 3 . They are similar apart from the iron content and its reduction state defined by Eq. (13).

\begin{tabular}{c|cccccccc} 
Glass & $\mathrm{SiO}_{2}$ & $\mathrm{Na}_{2} \mathrm{O}$ & $\mathrm{CaO}$ & $\mathrm{MgO}$ & $\mathrm{Al}_{2} \mathrm{O}_{3}$ & $\mathrm{Fe}$ & $\mathrm{S}$ & $\mathcal{R}^{\infty}$ \\
\hline 1 & 71.9 & 13.97 & 9.5 & 4 & 0.6 & 0.03 & $1 \cdot 10^{-2}$ & 0.57 \\
2 & 71.8 & 13.99 & 9.5 & 4 & 0.6 & 0.11 & $1 \cdot 10^{-2}$ & 0.42
\end{tabular}

Table 3: Composition of glasses in wt \% used in the experiments with the sufate content and the oxidation state. The iron content is the sum of the two polyvalent cations $\mathrm{Fe}^{2+}$, and $\mathrm{Fe}^{3+}$. The sulfate content is the sum of $\mathrm{SO}_{4}^{2-}$, and $\mathrm{SO}_{2}$.

\section{Scale analysis of the mass transfer of a $\mathrm{O}_{2}$ bubble}

The scale analysis requires to write the system of equations, Eqs. (1), (2), and (4), under a dimensionless form. These equations involve $N_{g}+2$ unknowns: $N_{g}$ gas species, bubble position, $z$, and radius, $a$. In order to simplify the analysis, the assumption about the pressure inside the bubble is presented in $§ 3.1$. After, the dimensionless equations describing the bubble composition is established in $§ 3.2$. A careful description of various time scales and also a new definition of the gas permeability as a function of gaseous species are presented in $\S 3.3$. Finally, an approximate solution is proposed in $\S 3.4$. This scale analysis is based on precepts introduced by Bejan (see chap. 1 of [4]). 


\subsection{Pressure inside the bubble}

If $a_{0}$ is the initial bubble radius, $a$ is normalized by

$$
\bar{a}=\frac{a}{a_{0}} .
$$

The local position of the bubble, $z$, is normalized with $H$ as

$$
\bar{z}=\frac{z}{H} .
$$

The pressure inside the bubble can be written as follows

$$
P=P_{0}\left[1+N_{g}(1-\bar{z})+\frac{N_{\sigma}}{\bar{a}}\right]
$$

where $N_{g}$ and $N_{\sigma}$ are given by

$$
\begin{aligned}
& N_{g}=\frac{\rho g H}{P_{0}}, \\
& N_{\sigma}=\frac{2 \sigma}{P_{0} a_{0}} .
\end{aligned}
$$

For $P_{0}=1$ bar, $N_{g}$ measuring the importance of hydrostatic pressure, is equal to 0.23 when $H$ is equal to one meter. Nevertheless, in the experimental conditions reported in [22] where $H=0.1 \mathrm{~m}, N_{h}$ is equal to $2.3 \cdot 10^{-2}$. The dimensionless number $N_{\sigma}$ is equal to $7 \cdot 10^{-3}$ for $a_{0}=1 \mathrm{~mm}$ with $P_{0}=1$ bar. Consequently, to a first approximation, the hydrostatic and Laplace pressures are neglected in the following developments.

In the other words, the pressure inside the bubble is assumed constant meaning that during the bubble motion, the hydrostatic part is not enough important to change significantly the total pressure. It is the same conclusion regarding the effect of the surface tension as long as the bubble is larger than $70 \mu \mathrm{m}$ corresponding to the bubble size obtaining when $N_{\sigma}=0.1$. This hypothesis simplifies the analysis since in this case, the coupled problem between gaseous species, bubble radius and position can be separated. Indeed, the requirement of the bubble position is not needed to describe the total pressure. Consequently, Eq. (4) is excluded in the following of this work.

Nevertheless, remark that even if the bubble position is not taken into account, the bubble motion remains important on the mass transfer process due to the low value of the mass diffusivity as it was showed in [21, 22]. 


\subsection{Dimensionless equations of mole number}

The total number of moles in a bubble can be estimated by the ideal gas law. The initial number of moles in the bubble is given by

$$
n_{0}=\frac{P_{0} 4 \pi a_{0}^{3}}{3 R T}
$$

If the dimensionless number of moles is written as follows

$$
\bar{n}=\frac{n}{n_{0}}
$$

and since the pressure is assumed constant, we have

$$
\bar{n}=\bar{a}^{3} .
$$

The number of moles of species $i$ is reduced as follows

$$
\bar{n}_{i}=\frac{n_{i}}{n_{0}},
$$

giving from the Dalton's law the relationship

$$
\bar{n}_{i}=x_{i} \bar{a}^{3},
$$

where $x_{i}$ is the molar fraction of gaseous species $i$ in the bubble. Since

$$
\sum_{i=1}^{N_{g}} x_{i}=1,
$$

the sum of $\bar{n}_{i}$ over the $N_{g}$ gaseous species is of course equal to $\bar{n}$.

So, Eq. (2), describing the time derivative of number of moles of gaseous species $i$, can be written under dimensionless form with the time reduced as follows

$$
\bar{t}=\frac{t}{\tau} .
$$

At this step, the characteristic time of the mass transfer, $\tau$, is an unknown quantity which has to be determined as a function of relevant phenomena describing the bubble shrinkage. To clearly define $\tau$, the various time scales involved in the mass transfer of a bubble have to be examined carefully.

From definition (22), the time derivative of the number of moles is given by

$$
\frac{1}{\tau} \frac{d\left(x_{i} \bar{a}^{3}\right)}{d \bar{t}}=-\frac{3 \overline{S h}_{i} \bar{a}\left(x_{i}^{\beta_{i}}-S a_{i, 0}\right)}{\tau_{i}} .
$$


In this last equation, $S a_{i, 0}$ is the saturation of gaseous species $i$ defined by

$$
S a_{i, 0}=\frac{C_{i}^{\infty}}{L_{i} P_{0}^{\beta_{i}}}
$$

This saturation is defined with the pressure $P_{0}$ as if the bubble was composed only of the gaseous species $i$. In order to remember this point, the symbol 0 is introduced on the lower index in $S a_{i, 0}$.

In Eq. (28), $\overline{S h}_{i}$ is defined by

$$
\overline{S h}_{i}=\frac{S h_{i}}{S h_{i, 0}}
$$

This quantity, resulting of the introduction of $S h_{i, 0}$ in $\tau_{i}$ (see the discussion below), is just the ratio of the Sherwood number for the bubble size $a$ to the one for the bubble size $a_{0}$. This quantity will be larger than one if the bubble grows and lesser than one if the bubble shrinks. It represents the effect of advection for the bubble size $a$ compared to the bubble size equal to $a_{0}$. It can be defined as a function of $\bar{a}$ as it will be done in the following.

The characteristic time for the mass transfer of gaseous species $i, \tau_{i}$, is given by

$$
\tau_{i}=\frac{2 a_{0}^{2} P_{0}^{1-\beta_{i}}}{S h_{i, 0} \mathcal{D}_{i} L_{i} R T}
$$

This quantity is easily derived by the introduction of the characteristic variables in eq. (2) defined for the initial bubble size. The division by the Sherwood number is done in order to take into account the bubble motion in the mass transfer. As it can be easily evaluated, the typical value of the Péclet number can exceed $10^{3}$ for which the Sherwood number is larger than 10. Consequently, without $S h_{i, 0}, \tau_{i}$ should be a diffusion time normalized with the bubble size which is irrelevant in the process mainly driven by the advection. Moreover, the oxidation-reduction reaction of iron oxides by oxygen is also taken into account when the Sherwood number is introduced in eq. (28) with the definition of $S h_{\mathrm{O}_{2}}$ and $P e_{\mathrm{O}_{2}}^{\prime}$ given in the previous section.

To establish (28), the molar concentration difference between the bubble surface and the bulk of molten glass is taken, leading to the occurrence of the solubility in $\tau_{i}$. Finally, it should be noted that the $L_{i} R T / P_{0}^{1-\beta_{i}}$ is a dimensionless number. 


\subsection{Permeability, and time scales, $\tau_{i}$, versus gas species}

To simplify again Eq. (25), it is important to have a clear idea about the time scale (28) as a function of gaseous species. Before to do that, the gas permeability is introduced.

The product $\mathcal{D}_{i} L_{i} R T / P_{0}^{1-\beta_{i}}$ in (28) depends on the diffusion but also on the solubility of gaseous species $i$. This quantity represents the rate of gas exchange between the two phases. So, for two species having the same diffusion coefficient, the respective characteristic time of mass transfer can be very different if their solubilities are very different. The product $\mathcal{D}_{i} L_{i}$ is usually defined as the permeability of gaseous species $i$, see for example [28]. However, we suggest to use the product $\mathcal{D}_{i} L_{i} R T / P_{0}^{1-\beta_{i}}$ since this quantity has the same unit as a diffusion coefficient, which is useful to compare with other relevant phenomena. Moreover, for water, the exponent $\beta_{i}$ is equal to $1 / 2$, and the permeability of water depends on the pressure: it is an important point for applications not present in the definition given by Shelby [28].

Consequently, the characteristic time, $\tau_{i}$, being inversely proportional to the permeability decreases with the permeability. The quantity $\tau_{i}$ was calculated for $\mathrm{O}_{2}, \mathrm{SO}_{2}, \mathrm{CO}_{2}$, $\mathrm{N}_{2}$ and $\mathrm{H}_{2} \mathrm{O}$ for temperatures and initial sizes presented in [22]. The diffusion coefficient and solubility of each species are taken from relationships depending on temperature summed up in Appendix A. The numerical values of $\tau_{i}$ are given in Table 4.

These characteristic times present a large range of values. Table 4 gives values of few seconds for water meaning that this gaseous species reaches very rapidly an equilibrium state. This result is mainly due to its large solubility. Water is chemically dissolved in molten glass [27]. Thus water solubility is a few order of magnitude larger than that of other species. At $1300{ }^{\circ} \mathrm{C}$ for example, the water solubility is $0.46 \mathrm{~mol} \cdot \mathrm{m}^{-3} \cdot \mathrm{Pa}^{-1 / 2}$ while the value for $\mathrm{N}_{2}$ is $1.6 \cdot 10^{-7} \mathrm{~mol} \cdot \mathrm{m}^{-3} \cdot \mathrm{Pa}^{-1}$. Consequently, the bubble is quickly filled with water with a molar fraction given by

$$
x_{\mathrm{H}_{2} \mathrm{O}}=S a_{\mathrm{H}_{2} \mathrm{O}, 0}^{2}
$$

This last equation comes from the cancellation of the right hand side of (25).

The mass transfer process is relatively fast for $\mathrm{SO}_{2}$ since the typical value is about three or four hundred seconds. The characteristic time of the mass transfer for oxygen 


\begin{tabular}{|c|c|c|c|c|c|}
\hline gas & $\mathrm{O}_{2}$ & $\mathrm{SO}_{2}$ & $\mathrm{CO}_{2}$ & $\mathrm{~N}_{2}$ & $\mathrm{H}_{2} \mathrm{O}$ \\
\hline$\tau_{i}(\mathrm{~s})$ & 1379 & 464 & 8686 & 78536 & 10 \\
\hline \multicolumn{6}{|c|}{ Glass $1, a_{0}=1.7 \mathrm{~mm}, T=1450{ }^{\circ} \mathrm{C}$} \\
\hline gas & $\mathrm{O}_{2}$ & $\mathrm{SO}_{2}$ & $\mathrm{CO}_{2}$ & $\mathrm{~N}_{2}$ & $\mathrm{H}_{2} \mathrm{O}$ \\
\hline$\tau_{i}(\mathrm{~s})$ & 1007 & 423 & 6914 & 53898 & 8 \\
\hline \multicolumn{6}{|c|}{ Glass $2, a_{0}=2.3 \mathrm{~mm}, T=1300{ }^{\circ} \mathrm{C}$} \\
\hline gas & $\mathrm{O}_{2}$ & $\mathrm{SO}_{2}$ & $\mathrm{CO}_{2}$ & $\mathrm{~N}_{2}$ & $\mathrm{H}_{2} \mathrm{O}$ \\
\hline$\tau_{i}(\mathrm{~s})$ & 3322 & 977 & 24630 & 310707 & 31 \\
\hline \multicolumn{6}{|c|}{ Glass $2, a_{0}=1 \mathrm{~mm}, T=1400{ }^{\circ} \mathrm{C}$} \\
\hline gas & $\mathrm{O}_{2}$ & $\mathrm{SO}_{2}$ & $\mathrm{CO}_{2}$ & $\mathrm{~N}_{2}$ & $\mathrm{H}_{2} \mathrm{O}$ \\
\hline$\tau_{i}(\mathrm{~s})$ & 850 & 398 & 7445 & 67056 & 9 \\
\hline
\end{tabular}

Table 4: Characteristic times of mass transfer of each gaseous species determined under experimental conditions (temperature and initial size of the observed bubble) for the two glasses.

is larger than the one obtained for sulfur dioxide. Moreover, note that the effect of the oxidation-reduction of iron is clearly established. The comparison of the time scale, $\tau_{i}$, obtained at $1400{ }^{\circ} \mathrm{C}$ for the two glasses shows that the characteristic time for glass 2 is 1.6 times lesser than for glass 1. The difference is not due to the initial bubble sizes which are unlike between the two glasses. At $T=1400^{\circ} \mathrm{C}$, the Péclet number for the bubble is larger than $10^{3}$ which means that the Sherwood number can be taken as a function of the square root of the Péclet number. In this limit, the Sherwood number scales as $a_{0}^{3 / 2}$. Consequently, the time scale $\tau_{i}$ for oxygen must be proportional to $\sqrt{a_{0}}$. Then, the ratio between the initial bubble size between the two glasses should give a time scale only 1.16 times lesser for the bubble observed in glass 2 . The characteristic time taking into account the effect of the oxidation-reduction reaction is more important due to the larger value of the Sherwood number in a glass where the iron content is more important.

Mass transfer processes for $\mathrm{CO}_{2}$, and $\mathrm{N}_{2}$ are very slow. The characteristic time, $\tau_{i}$, can reach a typical value larger than few thousand seconds for $\mathrm{CO}_{2}$, and larger than few ten thousand seconds for $\mathrm{N}_{2}$. Consequently, the filling-up of a bubble with $\mathrm{CO}_{2}$, and $\mathrm{N}_{2}$ can take a long time. 
From the numerical simulation presented in [22], molar fractions in the bubble can be determined in order to verify the conclusions drawn above. Fig. 1 presents $x_{i}$ as a function of time for the five species, $\mathrm{SO}_{2}, \mathrm{O}_{2}, \mathrm{CO}_{2}, \mathrm{~N}_{2}$ and $\mathrm{H}_{2} \mathrm{O}$ with the main figure, representing volume fraction after a time equal to one half of hour. The results were obtained with the properties of glass 2 at $T=1400{ }^{\circ} \mathrm{C}$. Two inserts are introduced in Fig. 1 in order to focus on the behavior of a bubble after very short time (Insert 1) and on very long time (Insert 2). This numerical result confirms the dimension analysis: water is rapidly in equilibrium between the two phases as it is shown in Insert 1 of Fig. 1. While the volume fractions of $\mathrm{N}_{2}$ and $\mathrm{CO}_{2}$ are small during the first few minutes, they become larger when time increases. In Insert 2 of Fig. 1, the volume fractions of $\mathrm{N}_{2}$ and $\mathrm{CO}_{2}$ are significant in the bubble.

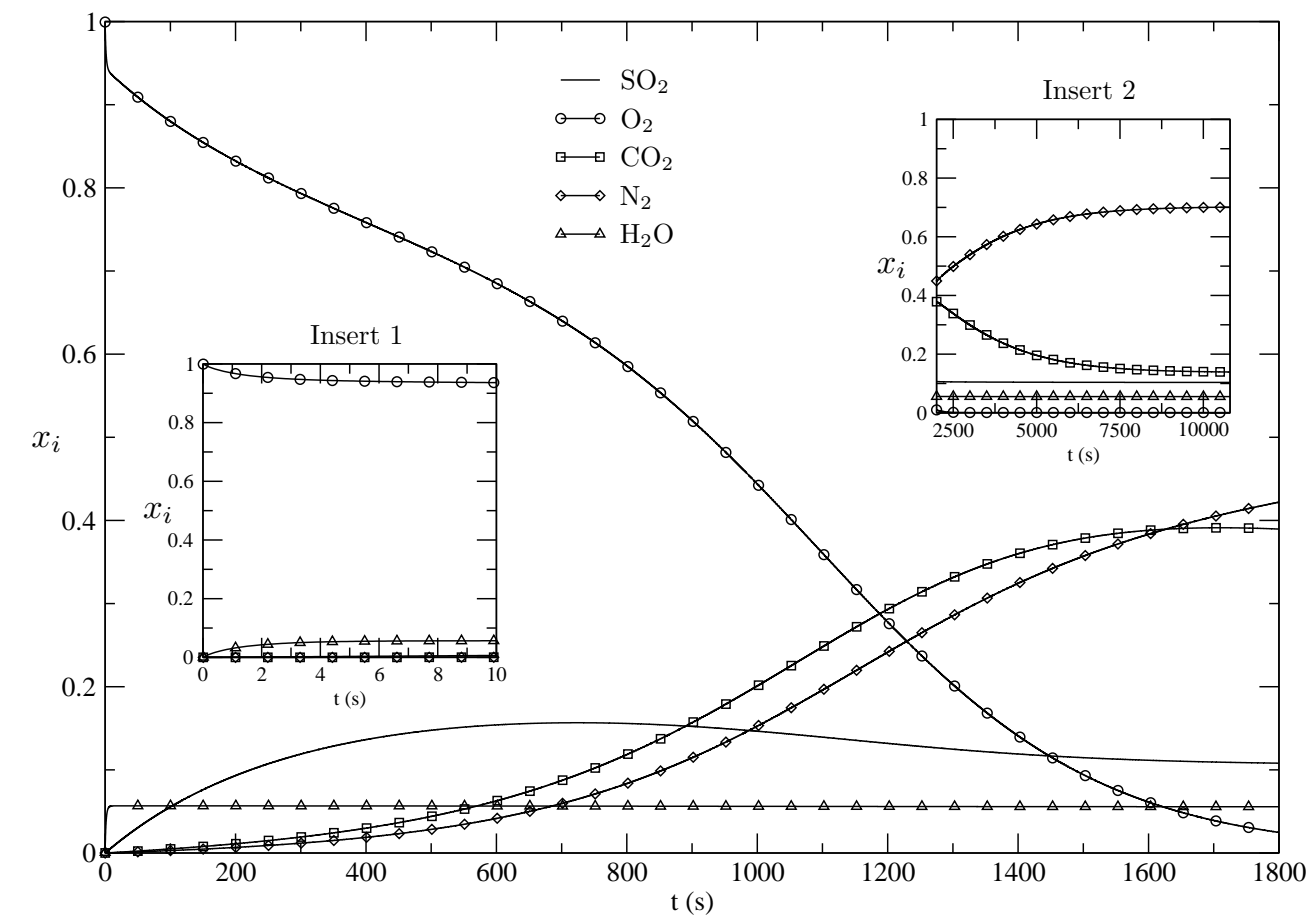

Figure 1: Molar fraction of gaseous species as a function of time in a bubble obtained from the numerical simulation with characteristics of glass 2 at $T=1400{ }^{\circ} \mathrm{C}$. Insert 1 gives molar fraction at very short time and Insert 2 at very long time.

Consequently, from this simple analysis, it is possible to establish a hierarchy of 
gaseous species entering or exiting of a bubble. Comparing to the typical time scale in glass melting process where the average residence time in a glass bath can exceed one day, water can be considered in an equilibrium state quasi-instantaneously. At very short times, since the bubble is composed mainly of oxygen, the introduction of water in the bubble produces a fast decrease of molar fraction of $\mathrm{O}_{2}$ as it can be seen in Fig 1. A bubble undergoes the introduction of $\mathrm{CO}_{2}$ and $\mathrm{N}_{2}$ over a typical time larger than few hours as a function of temperature.

This analysis can be useful in the feature of bubbles dispersed in an industrial plant, the composition of each bubble in a molten glass depending on its residence time. Consequently, gas analysis of bubble in a glass can give information about the origin of this defect.

\subsection{An approximate solution of bubble radius}

The time scale $\tau$ introduced in Eq. (25) can now be specified. From the previous analysis, the relevant species are $\mathrm{O}_{2}$, and $\mathrm{SO}_{2}$. The study is focused on oxygen bubble, so $\tau$ is taken equal to the characteristic time of mass transfer of oxygen, $\tau_{\mathrm{O}_{2}}$. The time derivative of the reduced bubble radius can be written as follows

$$
\frac{d \bar{a}}{d \bar{t}}=-\frac{1}{\bar{a}} \sum_{i=1}^{N_{g}} \frac{\overline{S h}_{i}}{\bar{\tau}_{i}}\left(x_{i}^{\beta_{i}}-S a_{i, 0}\right),
$$

where $\bar{\tau}_{i}$ is the reduced time scale of gaseous species $i$ defined by

$$
\bar{\tau}_{i}=\frac{\tau_{i}}{\tau_{\mathrm{O}_{2}}} .
$$

From Eq. (30) given above and Eq. (25), the time derivative of molar fraction $x_{i}$ in the bubble is given by

$$
\frac{d x_{i}}{d \bar{t}}=\frac{3}{\bar{a}^{2}} \sum_{j=1}^{N_{g}} \frac{\overline{S h}_{j}}{\bar{\tau}_{j}}\left(x_{j}^{\beta_{j}}-S a_{j, 0}\right)\left(x_{i}-\delta_{i j}\right),
$$

where $\delta_{i j}$ is the Kronecker symbol, equal to 1 if $i=j$ and equal to 0 if $i \neq j$.

Using these equations, it is possible to find an approximate solution of $\bar{a}$ at short times. In order to do that and according to the analysis given in the previous subsection, the bubble is assumed to be composed mainly of oxygen and water. Sulfur dioxide is also taken into account since its kinetics has been shown sufficiently fast to reduce the 
shrinkage rate. Moreover, if the Sherwood numbers are taken in the limit of large Péclet numbers $[5,13,21]$ (i.e. in the boundary layer regime), the ratio $\overline{S h}_{i}$ is directly equal to $\bar{a}^{3 / 2}$ as it has been shown in the subsection 3.3. In this limit, Eq. (30) can be easily integrated to give an explicit solution of bubble size variation:

$$
\bar{a}(\bar{t})=\left[1-\frac{1}{2}\left(1-x_{\mathrm{H}_{2} \mathrm{O}}-S a_{\mathrm{O}_{2}, 0}-\frac{S a_{\mathrm{SO}_{2}, 0}}{\bar{\tau}_{\mathrm{SO}_{2}}}\right) \bar{t}\right]^{2} .
$$

This relationship, one of the more important result of this paper is a generalized version of the solution already given by Onorato et al. [18], the multicomponent bubble being taken into account in the present work. Onorato et al. [18] derived their solution by taking into account the Laplace pressure which is not done here. Eq. (33) shows that the bubble radius is a quadratic function of time.

Table 5 summarizes the numerical values of quantities required to compute the solution (33) for the two specific glasses and for temperatures used in the experiments reported in [22]. Remark that from these data, both $\mathrm{O}_{2}$, and $\mathrm{SO}_{2}$ are under-saturated. Moreover, the molar fraction of water depends slightly on temperature.

\begin{tabular}{ccccc} 
& $T\left({ }^{\circ} \mathrm{C}\right)$ & $S a_{\mathrm{O}_{2}, 0}$ & $S a_{\mathrm{SO}_{2}, 0}$ & $x_{\mathrm{H}_{2} \mathrm{O}}$ \\
\hline Glass 1 & 1400 & $9.3 \cdot 10^{-5}$ & $1.1 \cdot 10^{-1}$ & $6 \cdot 10^{-2}$ \\
& 1450 & $2.68 \cdot 10^{-4}$ & $1.3 \cdot 10^{-1}$ & $6 \cdot 10^{-2}$ \\
\hline Glass 2 & 1300 & $1.1 \cdot 10^{-4}$ & $9.6 \cdot 10^{-2}$ & $6.2 \cdot 10^{-2}$ \\
& 1400 & $1.1 \cdot 10^{-3}$ & $1.1 \cdot 10^{-1}$ & $6 \cdot 10^{-2}$ \\
\hline
\end{tabular}

Table 5: $S a_{\mathrm{O}_{2}, 0}, \mathrm{Sa}_{\mathrm{SO}_{2}, 0}$, and $x_{\mathrm{H}_{2} \mathrm{O}}$ at different temperatures for the two glasses used in the present work.

In Fig. 2, the normalized bubble size is given as a function of dimensionless time, written as $\left(1-x_{\mathrm{H}_{2} \mathrm{O}}-S a_{\mathrm{O}_{2}, 0}-S a_{\mathrm{SO}_{2}, 0} / \bar{\tau}_{\mathrm{SO}_{2}}\right) \bar{t} / 2$, obtained from the experimental data for the two glasses used in this work. With this reduced form and with assumptions made above, all experimental data consist roughly of a master curve independent of temperature and the glass nature. In Fig. 2, the solution given by equation (33) is reported: at short times a good agreement is found between experimental results and this approximate solution for the two glasses.

When the time increases Eq. (33) underestimates the bubble size compared of experimental results meaning that the solution (33) becomes invalid. In fact, Eq. (33) has 


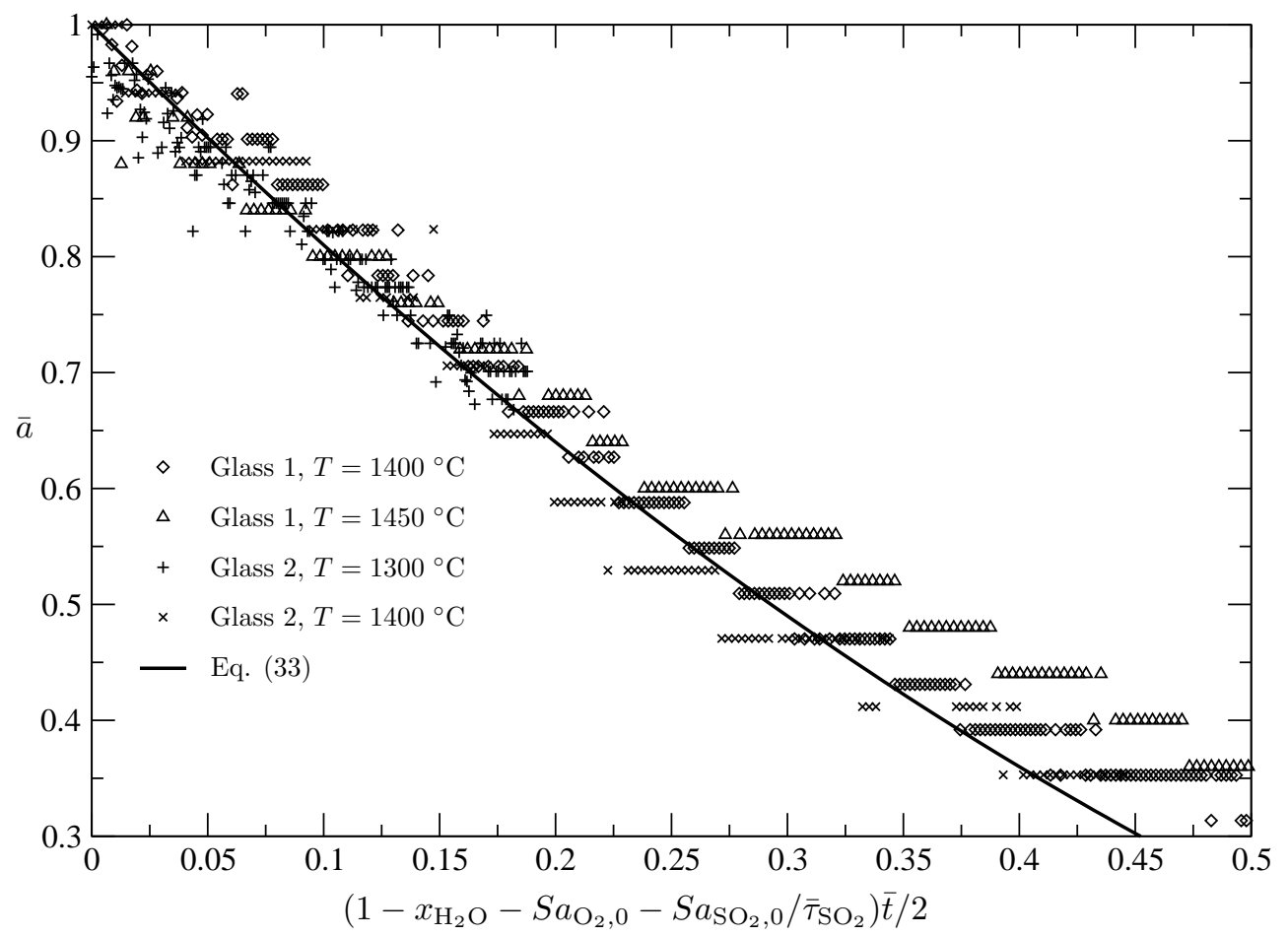

Figure 2: Normalized bubble size as a function of dimensionless time for the two glasses. Comparison between theoretical solution and experimental results.

been established assuming that the bubble composition does not change significantly. This point is valid as long as oxygen is the most important species inside the bubble. Consequently, the approximate solution (33) is relevant over the time scale of $\tau_{\mathrm{O}_{2}}$. Beyond this time, the bubble size behavior can change deeply as it is pointed out in [22].

From this analysis, the characteristic time to describe the shrinkage of an oxygen bubble can be written as follows

$$
\tau_{\mathrm{Sh}, \mathrm{O}_{2}}=\frac{2 a_{0}^{2}}{S h_{\mathrm{O}_{2}, 0} \mathcal{D}_{\mathrm{O}_{2}} L_{\mathrm{O}_{2}} R T\left(1-x_{\mathrm{H}_{2} \mathrm{O}}-S a_{\mathrm{O}_{2}, 0}-S a_{\mathrm{SO}_{2}, 0} / \bar{\tau}_{\mathrm{SO}_{2}}\right)} .
$$

This time differs from $\tau_{\mathrm{O}_{2}}$ by the division of $1-x_{\mathrm{H}_{2} \mathrm{O}}-S a_{\mathrm{O}_{2}, 0}-S a_{\mathrm{SO}_{2}, 0} / \bar{\tau}_{\mathrm{SO}_{2}}$ which is always lesser than one. The introduction of this last quantity in (34) enables to take into account the effects of water and sulfate dioxide. For the data reported in Tables 4 and 5 , the time scale (34) is around 50 or $60 \%$ larger than $\tau_{\mathrm{O}_{2}}$. As already discussed in the last subsection, this characteristic time takes into account most of phenomena occurring around an oxygen bubble shrinking in molten glass. Therefore, this time can 
be computed easily as a function of the bubble size and the glass nature.

\section{Conclusion}

The mass transfer of a multicomponent bubble rising in molten glass has been studied in this work. The general model to describe the composition and the size of a bubble is presented. To describe more clearly the effect of each gaseous species, a dimension analysis is proposed with the pressure inside a bubble assumed to be constant. A characteristic time related to mass transfer process for each gaseous species is proposed showing that the rate of exchange depends strongly on the gas nature.

The fundamental quantity involved in the mass transfer of a specific gaseous species is related to the product of the diffusion coefficient by the solubility, known as the permeability (see [28]). Here, a new definition of the permeability is proposed having the same unit as a diffusion coefficient.

From this analysis, we show that the equilibrium state between a bubble and molten glass is quickly reached for water. This result is due to the large solubility of water in molten glass, generally, few order of magnitude larger than for the other species. A reverse situation is observed for carbon dioxide and nitrogen. Consequently, the composition of a bubble in molten glass changes over a very long time.

In spite of the multicomponent feature of a bubble in molten glass, it is possible to consider only two gases, $\mathrm{O}_{2}$ and $\mathrm{SO}_{2}$ for the first times of the bubble shrinkage. Consequently, for a bubble initially composed of oxygen, a simplified equation of bubble size can be deduced with a characteristic time based only on the oxygen transfer. The range of application of the simplified solution is related to the change of bubble composition. Since the analysis is based on bubbles initially composed of $100 \%$ of $\mathrm{O}_{2}$, the bubble composition does not change over the characteristic time corresponding to the mass transfer of oxygen. Moreover, from this scaling analysis, experimental data giving the bubble size versus time (obtained for two glasses with different iron contents and various temperatures) match very well in a master curve. This calculation needs rescaling of the time with the proposed characteristic times based on the mass transfer of oxygen. Finally, the agreement between experimental data and the results given by this simplified equation of bubble size shows its relevance and that it can be useful to estimate quickly the bubble 
behavior without computing of the full problem.

Moreover, this analysis can give an important information about the residence time of a bubble in molten glass, the bubble composition changing as a function of its age in molten glass. Consequently, the experimental knowledge of a bubble composition could be used to determine the origin of a bubble defect in a furnace though the experimental determination of the bubble composition remains a difficult task in glass science.

The work has been focused on bubbles initially filled with $100 \%$ of oxygen. A similar analysis has to be done when a bubble is composed with another gas species.

\section{Acknowledgments}

The author is indebted to an anonymous referee form the various suggestions in the structure of this article and for the fruitful discussions.

\section{A. Physical and chemical properties of soda-lime-silica glass}

The solubilities used in section 3 are defined by the formula [2]

$$
L_{j}=A_{j}^{(S)} \exp \left(\frac{B_{j}^{(S)}}{T}\right) .
$$

The solubility is given in $\mathrm{mol} \cdot \mathrm{m}^{-3} \cdot \mathrm{Pa}^{-1}$ for most species and in $\mathrm{mol} \cdot \mathrm{m}^{-3} \cdot \mathrm{Pa}^{-1 / 2}$ for

water vapor. The coefficients $A_{j}^{(S)}$ and $B_{j}^{(S)}$ for gases discussed in this work are listed in Table 6 .

\begin{tabular}{c|ccccc} 
Gas & $\mathrm{O}_{2}$ & $\mathrm{SO}_{2}$ & $\mathrm{CO}_{2}$ & $\mathrm{~N}_{2}$ & $\mathrm{H}_{2} \mathrm{O}$ \\
\hline$A_{j}^{(S)}$ & $1.37 \cdot 10^{-4}$ & $6.44 \cdot 10^{-7}$ & $5.6 \cdot 10^{-7}$ & $1.1 \cdot 10^{-5}$ & $6.8 \cdot 10^{-1}$ \\
$B_{j}^{(S)}$ & -6633 & 7860 & 3120 & -6633 & -613
\end{tabular}

Table 6: Numerical values of $A_{j}^{(S)}$ and $B_{j}^{(S)}$ used to determine the solubilities of dissolved gaseous species in soda-lime-silica glass taken from [2].

The diffusion coefficients of dissolved species are given in $\mathrm{m}^{2} \cdot \mathrm{s}^{-1}$ and expressed as follows

$$
\mathcal{D}_{j}=A_{j}^{(D)} \exp \left(\frac{B_{j}^{(D)}}{T}\right),
$$

where the coefficients $A_{j}^{(D)}$ and $B_{j}^{(D)}$ are summarized in Table 7 . 


\begin{tabular}{c|ccccc} 
Gas & $\mathrm{O}_{2}$ & $\mathrm{SO}_{2}$ & $\mathrm{CO}_{2}$ & $\mathrm{~N}_{2}$ & $\mathrm{H}_{2} \mathrm{O}$ \\
\hline$A_{j}^{(D)}$ & $3 \cdot 10^{-3}$ & $4.45 \cdot 10^{-7}$ & $1.92 \cdot 10^{-5}$ & $4.3 \cdot 10^{-5}$ & $1.2 \cdot 10^{-5}$ \\
$B_{j}^{(D)}$ & -26580 & -15360 & -21516 & -19364 & -18320
\end{tabular}

Table 7: Numerical values of $A_{j}^{(D)}$ and $B_{j}^{(D)}$ used to determine the diffusion coefficients of dissolved gaseous species in soda-lime-silica glass taken from [2].

\section{References}

[1] R. G. C. Beerkens. Modeling of the melting process in industrial glass furnaces. In Mathematical simulation in glass technology, chapter 2.1, pages 17-73. Springer, Berlin, 2002.

[2] R. G. C. Beerkens. Analysis of advanced and fast fining processes for glass melts. In Advances in Fusion and Processing of Glass III, pages 3-24. American Ceramic Society, New York, 2003.

[3] R. G. C. Beerkens and H. de Waal. Mechanism of oxygen diffusion in glassmelts containing variablevalence ions. J. Am. Ceram. Soc., 73:1857-1861, 1990.

[4] A. Bejan. Convection heat transfer. John Wiley \& Sons, New York, 1995.

[5] R. Clift, J. R. Grace, and M. E. Weber. Bubbles, Drops, and Particles. Academic Press, New York, 1978.

[6] R. H. Doremus. Diffusion of oxygen from contracting bubbles in molten glass. J. Amer. Ceram. Soc., 43:655-661, 1960.

[7] C. H. Greene and R. F. Gaffney. Apparatus for measuring the rate of absorption of a bubble in glass. J. Amer. Ceram. Soc., 42:271-275, 1959.

[8] C. H. Greene and I. Kitano. Rate of solution of oxygen bubbles in commercial glasses. Glastech. Ber., $32 \mathrm{~K}(\mathrm{~V}): 44-48,1959$.

[9] C. H. Greene and H. A. Lee. Effect of As2O3 and NaNO3 on the solution of O2 in soda-lime glass. J. Amer. Ceram. Soc., 48:528-533, 1965.

[10] C. H. Greene and D. R. Platts. Behavior of bubbles of oxygen and sulfur dioxide in soda-lime glass. J. Amer. Ceram. Soc., 52:106-109, 1969.

[11] H. Hirashima, T. Yoshida, and R. Brückner. Redox equilibria and constitution of polyvalent ions in oxide melts and glasses. Glastech. Ber., 61:283-292, 1988.

[12] J. Kloužek and L. Němec. Modelling of glass refining kinetics. Part 2: Bubble distribution models and methods of measurement of refining properties. Ceramics, 47:155-161, 2003.

[13] V. G. Levich. Physicochemical hydrodynamics. Prentice Hall, Englewood Cliffs, N.J., 1962.

[14] B. O. Mysen and P. Richet. Silicate Glasses and Melts: Properties and Structure. Elsevier, Amsterdam, 2005.

[15] L. Němec. The behaviour of bubbles in glass melts. Part 1: bubble size controlled by diffusion. Glass Technol., 21:134-138, 1980.

[16] L. Němec. The behaviour of bubbles in glass melts. Part 2: Bubble size controlled by diffusion and chemical reaction. Glass Technol., 21:139-144, 1980. 
[17] L. Němec and J. Kloužek. Modelling of glass refining kinetics. Part 1: single bubbles. Ceramics, 47:81-87, 2003.

[18] P. I. K. Onorato, M. C. Weinberg, and D. R. Uhlmann. Behavior of bulles in glassmelts: III, Dissolution and growth of a rising bubble containing a single gas. J. Am. Ceram. Soc., 64:676-682, 1981.

[19] A. Paul. Chemistry of glasses. Chapman and Hall, London, 1990.

[20] F. Pigeonneau. Coupled modelling of redox reactions and glass melt fining processes. Glass Technol.: Eur. J. Glass Sci. Technol. A, 48(2):66-72, 2007.

[21] F. Pigeonneau. Mass transfer of rising bubble in molten glass with instantaneous oxidation-reduction reaction. Chem. Eng. Sci., 64:3120-3129, 2009.

[22] F. Pigeonneau, D. Martin, and O. Mario. Shrinkage of oxygen bubble rising in a molten glass. Chem. Eng. Sci., 65:3158-3168, 2010.

[23] L. Pilon, A. G. Fedorov, D. Ramkrishna, and R. Viskanta. Bubble transport in three-dimensional laminar gravity-driven flow - mathematical formulation. J. Non-Cryst. Solids, 336:71-83, 2004.

[24] J. I. Ramos. Behavior of multicomponent gas bubbles in glass melts. J. Am. Ceram. Soc., 69:149154,1986

[25] D. W. Readey and A. R. Cooper. Molecular diffusion with a moving boundary and spherical symmetry. Chem. Eng. Sci., 21:917-922, 1966.

[26] S. S. Sadhal, P. S. Ayyaswamy, and J. N. Chung. Transport phenomena with drops and bubbles. Springer-Verlag, New York, 1997.

[27] H. Scholze. Gases in glass. In Proceeding of the 8th International Congres on Glass, Londres, 1968.

[28] J. E. Shelby. Introduction to Glass Science and Technology. The Royal Society of Chemistry, Cambridge, 1997.

[29] R. S. Subramanian and B. Chi. Bubble dissolution with chemical reaction. Chem. Eng. Sci., 35:2185-2194, 1980.

[30] H. Yoshikawa and Y. Kawase. Significance of redox reactions in glass refining processess. Glass Sci. Technol., 70:31-39, 1997. 